\title{
Memory Allocation of Automated VM on a Server in Cloud
}

\author{
S. Pothumani, C. Anuradha, S. Sangeetha
}

\begin{abstract}
VMMs keep memory utilizing those four previously been coordinated into the mainline portions. This variant offers the shopper solicitation to the server for the memory allocation. In this, we devise a mellow weight structure dependent on the Xen expand intention power to oversee memory inside the server of the VM's. Our purchaser which is going to show does never again meddle with the VM's. We have sorts of planning one is GLOBAL and diverse one is SELF scheduling. This principle thought is to "Procedure MEMORY ALLOCATION". In this we're especially going to utilize the ballon calculation directly here
\end{abstract}

Keyword: VMMs, VM's, memory allocation, server

\section{INTRODUCTION}

Virtualization has resurged as a result of distributed computing. More and additional bundles are sent into virtual machines (VMs) to multiplex a physical server. Programmed control frameworks for CPU contraptions have been generally examined anyway time sharing for memory gadgets remains an open issue, Tools for automated memory control at the product level require also look into. To start off basic components and to produce low-organize interfaces, Xen, VMware, and KVM have executed page sharing, computerized hot attachments, and inflatable drivers inside the VMM. Nonetheless, these systems and interfaces best mindfulness at the fundamental techniques in part mode to resize the memory for an individual VM. Along these lines, over the top degree equips in client mode are crucial to precisely assemble memory use from VMs, settle on worldwide choices and alter their memory. Memory planning calculations should be increasingly versatile to unique consequences, paying little mind to when the overall memory is sufficient or inadequate. EachVM can post a memory esteem, called committed memory.

Our past compositions focused easiest at the adequate country. Memory booking calculations should be in an adequate state, and self-expanding ends up not saw with an overall point of view. In this watch, we devise a lightweight system dependent on the Xen expand driver to control memory inside the solidification of more than one VMs. Our machine is applied in client region that doesn't meddle with VMM activity. For this structure, we propose an around the world booking calculation that keeps running on Domain0. This arrangement of guidelines understands straight

Revised Manuscript Received on December 11, 2019

S.Pothumani, Department of Computer Science and Engineering, Bharath Institute of Higher Education and Research, Chennai, India.

C.Anuradha, Department of Computer Science and Engineering, Bharath Institute of Higher Education and Research, Chennai, India.

S.Sangeetha, Department of Computer Science and Engineering, Bharath Institute of Higher Education and Research, Chennai, India. conditions to accomplish the overall arrangement and adjusts to adequate and inadequate states the utilization of dynamic baselines. Genuine worldwide benchmarks are received as remaining tasks at hand in our examinations, and $10 \mathrm{VMs}$ are applied. The unwinding of this paper is set up as pursues. We offer an outline of our memory control gadget and its execution. We depict the memory booking calculation. The test impacts are provided. We talk related examinations. At last, we convey finishing up comments and tips for predetermination thinks about.

\section{RELATED WORKS}

In this current gadget, Memory is then occasionally reallocated the use of this inflatable main thrust. Be that as it may, our machine has 3 extraordinary endowments over MEB. Initially, MEB adjusts the VMM piece to catch memory get admission to and uncover memory use. This strategy produces substantial extra over-burdens and decays VMM generally execution. Nonetheless, our device is light-weight and can be totally included into individual space without meddling with VMM activity. Second, MEB utilizes a concise estimation calculation to anticipate complete site page misses from arriving at an area insignificant. Our framework decides the most valuable distribution of world memory by methods for presenting dynamic baselines and settling straight conditions. Our device can choose the allotment with the guide of fixing direct conditions with the dynamic gauge, which fits every enough and insufficient real memory.

\section{PROPOSED SYSTEM}

We have advanced two planning calculations for the Server: self-booking and worldwide booking. Oneself planning set of guidelines is done if the free edges in the substantial machine can satisfy the general pages asked by all VMs. The global planning calculation is applied if the substantial framework needs loosened casings and can't meet the entire pages mentioned through all VMs. Customer gathers memory measurements from Domain and intermittently ignores this data to the Database. The booking calculation of Server at that point decides the zone that requires extra pages, notwithstanding the area that offers those additional pages. The planning set of principles furthermore figures the highest point of the line objective pages for allotment to each space.

Published By:

Blue Eyes Intelligence Engineering 


\section{Memory Allocation of Automated VM on a Server in Cloud}

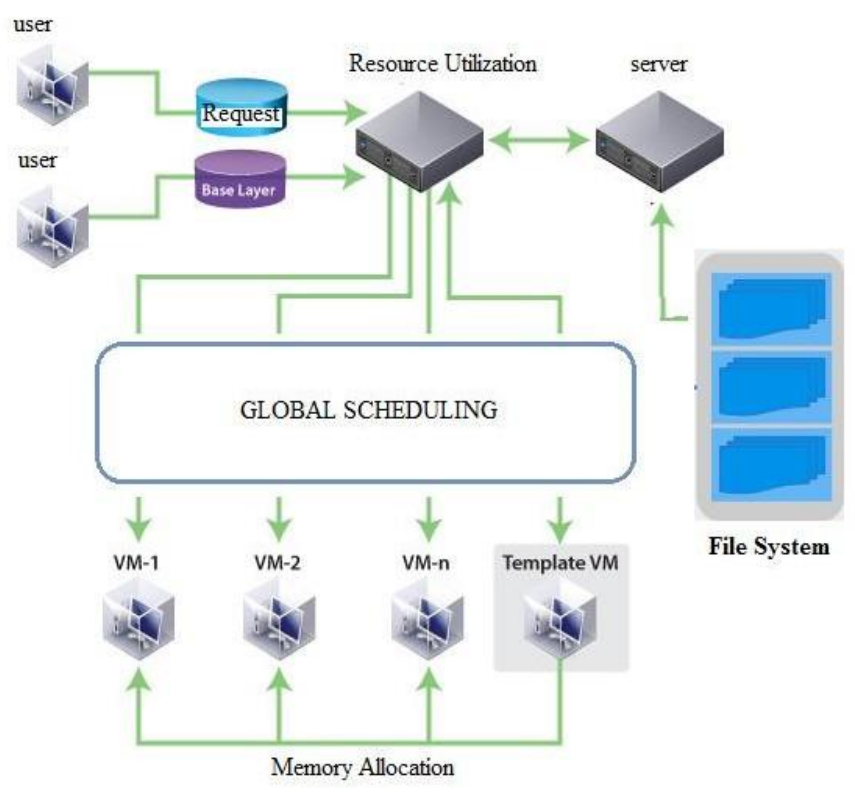

Figure1. Architecture diagram

First, the user requests the resource via resource utilization component. This is connected with server and global scheduling component. The server is connected with file system to upload, download and update the file systems. Global scheduling uses a global scheduling algorithm to allocate memory between different numbers of VMs.

\section{IMPLEMENTATION}

\section{A. PHYSICAL MACHINES}

substantial machines strategy building intelligent real projects by methods for application and equipment that may think and react to the simple world.[clarification needed] while this definition is incredible copious to epitomize procedures like shrewd auto traffic control frameworks or assembling office robotization techniques, it's not every now and again used to clarify them. In a more extensive consider, substantial registering is a clever structure for making sense of individuals' relationship to the advanced world. In valuable use, the time interim most frequently depicts high quality work of art, structure or DIY interest extends that utilization sensors and microcontrollers to make an interpretation of simple enter to a program approach, as well as control electro-mechanical instruments equal to engines, servos, lights or exceptional equipment. Physical Computing crosses the scope of leisure activities quite often alluded to in the scholarly community and friends as electrical designing, mechatronics, mechanical technology, pc science, and particularly implanted improvement. Our memory oversee strategy is executed in C, along the edge of Server, Database, and customer.

\section{B.VIRTUALCOMPUTING DEVICE}

A virtual PC is a program that goes about as a computerized registering gadget. It keeps running for your reward working methodology - the "have" working technique - and presents advanced equipment to "visitor" working strategies. The voyager walking techniques keep running in home windows in your host working method, indistinguishable from each unique application to your pc. The guest running

methodology runs for the most part, as though it had been running on a physical PC - from the guest working strategy's perspective, the computerized processing gadget gives off an impression of being a real, substantial PC. Computerized machines outfit their have virtual equipment, including an advanced CPU, memory, troublesome vitality, network interface, and different contraptions. The advanced equipment instruments outfitted by methods for the virtual processing device are mapped to explicit equipment to your real figuring device. For representation, a virtual processing gadget's virtual troublesome circle is spared in a document situated to your intense power.

\section{RESULTS}

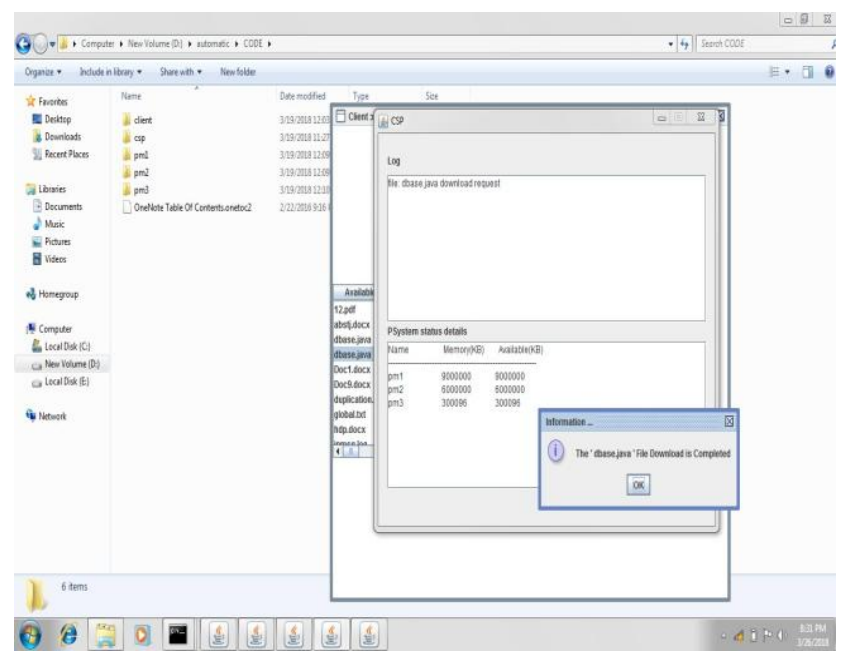

Figure2. File downloading

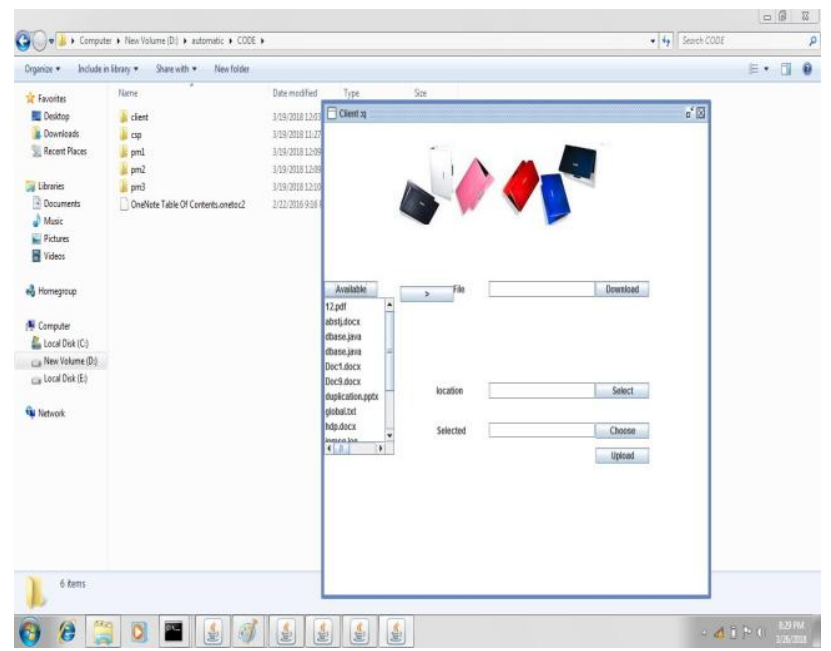

Figure3. File Transferring

Our framework aspirations to upgrade the taking strolls examples of purposes in merged situations by means of overbooking and additionally adjusting the memory pages of xen vms. Dislike ordinary ways, practically identical to meb, our procedure is light-weight and can becompletely incorporated into client space without meddling with vmm activity. We likewise plan a worldwide schedulingalgorithm dependent on the dynamic gauge to survey the preeminent distribution of memory comprehensively. 


\section{CONCLUSION}

Our methodology likewise proposals at the use of the test dispatcher to adjust asset usage in cloud situations with several real machines; when the cloud dispatcher plans obligations for physical machines, it should set up various types of purposes to VMs on one real work area. Especially, a most noteworthy of 1 plate serious application should be discharged alongside circle or memory-escalated purposes. By and by, mechanized memory control should be initiated if numerous memory serious capacities are kept running on one substantial work area.

\section{REFERENCES}

1. Kaliyamurthie, K.P., Sivaraman, K., Ramesh, S. Imposing patient data privacy in wireless medical sensor networks through homomorphic cryptosystems 2016, Journal of Chemical and Pharmaceutical Sciences

2. Kaliyamurthie, K.P., Balasubramanian, P.C. An approach to multi secure to historical malformed documents using integer ripple transfiguration 2016 Journal of Chemical and Pharmaceutical Sciences.

3. A.Sangeetha, C.Nalini,"Semantic Ranking based on keywords extractions in the web", International Journal of Engineering \& Technology, 7 (2.6) (2018) 290-292

4. S.V.GayathiriDevi,C.Nalini,N.Kumar,"An efficient software verification using multi-layered software verification tool "International Journal of Engineering \& Technology, 7(2.21)2018 454-457

5. C.Nalini,ShwtambariKharabe,"A Comparative Study On Different Techniques Used For Finger - Vein Authentication", International Journal Of Pure And Applied Mathematics, Volume 116 No. 8 2017, 327-333, Issn: 1314-3395

6. M.S. Vivekanandan and Dr. C. Rajabhushanam, "Enabling Privacy Protection and Content Assurance in Geo-Social Networks", International Journal of Innovative Research in Management, Engineering and Technology, Vol 3, Issue 4, pp. 49-55, April 2018.

7. Dr. C. Rajabhushanam, V. Karthik, and G. Vivek, "Elasticity in Cloud Computing", International Journal of Innovative Research in

Management, Engineering and Technology, Vol 3, Issue 4, pp. 104-111, April 2018

8. K. Rangaswamy and Dr. C. Rajabhushanamc, "CCN-Based Congestion Control Mechanism In Dynamic Networks", International Journal of Innovative Research in Management, Engineering and Technology, Vol 3, Issue 4, pp. 117-119, April 2018

9. Kavitha, R., Nedunchelian, R., "Domain-specific Search engine optimization using healthcare ontology and a neural network backpropagation approach", 2017, Research Journal of Biotechnology, Special Issue 2:157-166

10. Kavitha, G., Kavitha, R., "An analysis to improve throughput of high-power hubs in mobile ad hoc network" , 2016, Journal of Chemical and Pharmaceutical Sciences, Vol-9, Issue-2: 361-363

11. Kavitha, G., Kavitha, R., "Dipping interference to supplement throughput in MANET", 2016, Journal of Chemical and Pharmaceutical Sciences, Vol-9, Issue-2: 357-360

12. Michael, G., Chandrasekar, A.,"Leader election based malicious detection and response system in MANET using mechanism design approach", Journal of Chemical and Pharmaceutical Sciences(JCPS) Volume 9 Issue 2, April - June 2016.

13. Michael, G., Chandrasekar, A.,"Modeling of detection of camouflaging worm using epidemic dynamic model and power spectral density", Journal of Chemical and Pharmaceutical Sciences(JCPS) Volume 9 Issue 2, April - June 2016 .

14. Pothumani, S., Sriram, M., Sridhar, J., Arul Selvan, G., Secure mobile agents communication on intranet,Journal of Chemical and Pharmaceutical Sciences, volume 9, Issue 3, Pg No S32-S35, 2016

15. Pothumani, S., Sriram, M., Sridhar, Various schemes for database encryption-a survey, Journal of Chemical and Pharmaceutical Sciences, volume 9, Issue 3, Pg NoS103-S106, 2016

16. Pothumani, S., Sriram, M., Sridhar, A novel economic framework for cloud and grid computing, Journal of Chemical and Pharmaceutical Sciences, volume 9, Issue 3, Pg No S29-S31, 2016

17. Priya, N., Sridhar, J., Sriram, M. "Ecommerce Transaction Security Challenges and Prevention Methods- New Approach” 2016 ,Journal of Chemical and Pharmaceutical Sciences, JCPS Volume 9 Issue 3.page no:S66-S68
18. Priya, N.,Sridhar,J.,Sriram, M."Vehicular cloud computing security issues and solutions" Journal of Chemical and Pharmaceutical Sciences(JCPS) Volume 9 Issue 2, April - June 2016

19. Priya, N., Sridhar, J., Sriram, M. "Mobile large data storage security in cloud computing environment-a new approach" JCPS Volume 9 Issue 2. April - June 2016

20. Anuradha.C, Khanna.V, "Improving network performance and security in WSN using decentralized hypothesis testing "Journal of Chemical and Pharmaceutical Sciences(JCPS) Volume 9 Issue 2, April - June 2016

21. Anuradha.C, Khanna.V, "A novel gsm based control for e-devices" Journal of Chemical and Pharmaceutical Sciences(JCPS) Volume 9 Issue 2, April - June 2016.

22. Anuradha.C, Khanna.V, "Secured privacy preserving sharing and data integration in mobile web environments " Journal of Chemical and Pharmaceutical Sciences(JCPS) Volume 9 Issue 2, April - June 2016.

\section{AUTHORS PROFILE}

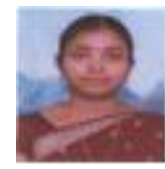

S.Pothumani, Assistant Professor, Department of Computer Science \& Engineering, Bharath Institute of Higher Education and Research, Chennai, India

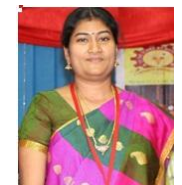

C.Anuradha, Assistant Professor, Department of Computer Science \& Engineering, Bharath Institute of Higher Education and Research, Chennai, India

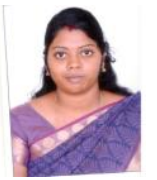

S.Sangeetha, Assistant Professor, Department of Computer Science \& Engineering, Bharath Institute of Higher Education and Research, Chennai, India 